\title{
Association between oral antimalarial medication administration and mortality among patients with Ebola virus disease: a multisite cohort study
}

Logan Abel ${ }^{1}$, Shiromi M. Perera², Derrick Yam³ ${ }^{3}$, Stephanie Garbern ${ }^{4}$, Stephen B. Kennedy ${ }^{5}$, Moses Massaquoi $^{5}$, Foday Sahr ${ }^{6}$, Dayan Woldemichael², Tao Liu ${ }^{3}$, Adam C. Levine ${ }^{4}$ and Adam R. Aluisio ${ }^{*}$

\begin{abstract}
Background: Empiric antimalarial treatment is a component of protocol-based management of Ebola virus disease $(E V D)$, yet this approach has limited clinical evidence for patient-centered benefits.

Methods: This retrospective cohort study evaluated the association between antimalarial treatment and mortality among patients with confirmed EVD. The data was collected from five International Medical Corps operated Ebola Treatment Units (ETUs) in Sierra Leone and Liberia from 2014 through 2015. The standardized protocol used for patient care included empiric oral treatment with combination artemether and lumefantrine, twice daily for three days; however, only a subset of patients received treatment due to resource variability. The outcome of interest was mortality, comparing patients treated with oral antimalarials within 48-h of admission to those not treated. Analysis was conducted with logistic regression to generate adjusted odds ratios (aORs). Multivariable analyses controlled for ETU country, malaria rapid diagnostic test result, age, EVD cycle threshold value, symptoms of bleeding, diarrhea, dysphagia and dyspnea, and additional standard clinical treatments.
\end{abstract}

Results: Among the 424 cases analyzed, 376 (88.7\%) received early oral antimalarials. Across all cases, mortality occurred in 57.5\% (244). In comparing unadjusted mortality prevalence, early antimalarial treated cases yielded $55.1 \%$ mortality versus $77.1 \%$ mortality for those untreated $(p=0.005)$. Multivariable analysis demonstrated evidence of reduced aOR for mortality with early oral antimalarial treatment versus non-treatment ( $\mathrm{aOR}=0.34,95 \%$ Confidence Interval: $0.12,0.92, p=0.039$ ).

Conclusion: Early oral antimalarial treatment in an EVD outbreak was associated with reduced mortality. Further study is warranted to investigate this association between early oral antimalarial treatment and mortality in EVD patients.

Keywords: Ebola virus disease, Malaria, West Africa, Mortality

*Correspondence: adam_aluisio@brown.edu

${ }^{4}$ Department of Emergency Medicine, Warren Alpert Medical School of Brown University, 55 Claverick Street, Room 274, Providence, RI 02903,

USA

Full list of author information is available at the end of the article

\section{Introduction}

The 2014-16 Ebola virus disease (EVD) epidemic in West Africa was the largest since the discovery of the virus in 1976 [1]. The mortality of EVD is high, averaging around $50 \%$, although varies greatly, ranging from 25 to $90 \%$ across outbreak and treatment settings [1]. EVD is found 
in areas endemic to other infectious diseases and it can be difficult to differentiate EVD from other infectious diseases during initial evaluations [1]. Malaria, which is highly endemic in West Africa, can present with similar symptoms to EVD and was common among patients presenting to Ebola Treatment Units (ETUs), including among EVD-positive patients during the 2014-16 epidemic [1-7]. The World Health Organization (WHO) guidelines recommend empiric antimalarial treatment for patients with suspected EVD [8], and as such antimalarial medications are commonly given in EVD treatment protocols [2-4, 9-23].

Multiple antimalarial medications have been shown to have activity against the Ebola Virus (EBOV) in laboratory studies. Amodiaquine, mefloquine, and chloroquine inhibit cellular entry of EBOV in vitro [24-30]. However, conflicting results on the survival impacts with chloroquine treatment in EVD animal models have been reported [24-26, 31-34]. Furthermore, there exists limited clinical evidence for improvements in patient-centered outcomes with the use of empiric antimalarials in EVD care from outbreak settings [13, 23, 35].

During the course of the West Africa EVD outbreak, International Medical Corps (IMC) operated five ETUs, three in Sierra Leone and two in Liberia, with local partners, providing care to over 2,500 patients, including 478 with confirmed EVD. The three ETUs in Sierra Leone received patients who were triaged by a government run District Ebola Response Center, and the two ETUs in Liberia received all patients in their respective geographic areas. All of the ETUs followed IMC guidelines that were developed based on guidance from the WHO and Médecins Sans Frontières collected in previous outbreak settings [36]. Given the frequent use of antimalarial medications in EVD treatment and the limited data on clinical impact, this study evaluated the association between early treatment with the oral antimalarial agent combination artemether-lumefantrine on mortality in patients with EVD using the multinational IMC database.

\section{Methods}

\section{Study design, setting and population}

The data for this retrospective multisite study were derived from five ETUs operated by IMC from 15 September 2014 through 31 December 2015 in Liberia and Sierra Leone [36]. The Sierra Leone Ethics and Scientific Review Committee, the University of Liberia and Rhode Island Hospital Institutional Review Boards provided ethical approval for this study and waived informed consent. Data from those clinical sites were collected during routine patient care and combined into a robust, multi-site database which has previously been employed to assess care provision and patient outcomes in EVD
[35-38]. The database was created from the original patient charts by trained staff using standardized clinical records, and data validation and standardization was conducted followed by audits of the data to ensure integrity. Lot quality assurance sampling (LQAS) methods, as previously reported, identified data accuracy at 99\% consistency [36]. All patients admitted to the ETUs, who had a final diagnosis of EVD and data on oral antimalarial treatment and mortality were eligible for inclusion. Patients were considered as a part of the treatment group if they received oral antimalarial treatment, regardless of whether or not they received IV antimalarials, given that only a small number of patients received IV antimalarials. Patients who died before ETU triage assessments were excluded.

\section{Clinical procedures}

All patients received care from trained practitioners who used standardized guidelines developed by IMC in consultation with local and trans-national bodies for the treatment of EVD (Additional file 1). The guidelinebased care recommended artemether-lumefantrine for all patients, 4 tablets by mouth twice a day for 3 days for adults. For children less than $35 \mathrm{~kg}(\mathrm{~kg})$, dosing for artemether-lumefantrine was weight based (Additional file 1). Patients unable to take oral antimalarials or who were deemed to have severe malaria were treated with IV antimalarials (artemether or artesunate) until oral medications could be tolerated [39]. Malaria rapid diagnostic test (RDT) results were reported as positive, negative, or not performed for all ETU patients. When undertaken, patients were tested for malaria, using the BinaxNow ${ }^{\mathrm{M}}$ RDT which detects antigens from the Plasmodium species of Ovale, Vivax, Malariae, and Falciparum [40]. Patients were tested for malaria when the resources were available and when the staff decided an RDT was clinically helpful. EVD testing was carried out using the real-time reverse transcription polymerase chain reaction (RT-PCR) assays. EVD cycle threshold (CT) values (inversely proportional to viral load) were coded as three categories of $>22$ (low viral load), $\leq 22$ (high viral load), and missing when results were not available [41].

\section{Statistical analysis}

Statistical analyses were completed using R (Version 1.2.1335) statistical software [42]. Descriptive statistics were conducted for the study population with means and standard deviations (SD) or medians with interquartile ranges (IQR) for continuous variables, and frequencies with corresponding percentages calculated for categorical variables as appropriate. The primary study outcome was mortality during ETU care. Due to the potential for survivor bias derived from the high observed 
early mortality in this patient population [43], early oral antimalarial treatment was chosen as the primary predictor variable. Early empiric treatment with oral antimalarials was defined as the initiation of treatment with artemether-lumefantrine within the first $48 \mathrm{~h}$ of ETU admission. Missing data was present only for RDT and CT assay values, as such this was not corrected for as missing data was not random - patients who died earlier in ETU care were more likely to have missing laboratory data. Due to this, correction for the missing data could bias the results, as has been described in other EVD studies $[37,38,41]$.

Inferential analyses were conducted comparing characteristics between the treated and untreated oral antimalarials groups, and between patients that lived and died. Pearson chi-square tests or Fischer's exact test were used for categorical variables and student's t-tests or rank-sum tests were used for continuous variables as appropriate. Multivariable logistic regression models for the outcome of mortality during ETU care were constructed to generate adjusted odds ratios (aORs) with associated 95\% confidence intervals (CI). Variable selection for inclusion in the multivariable modeling were based on identified evidence of difference $(\mathrm{p}<0.05)$ in the bivariate analyses as well as on previous literature demonstrating associations with mortality in EVD. The variables included in the multivariable models, based on past literature, included: multivitamin (MVI) treatment [44], Cefixime treatment [45], clinical signs and symptoms of bleeding, diarrhea, dyspnea, and dysphagia [7], initial CT value and age [43]. Age was modeled with a cubic spline due to the previously documented quadratic relationship between age and mortality in EVD [43]. As treatments with MVI, Vitamin C and Vitamin A, were found to be colinear in the data, MVI treatment, which included both Vitamin $A$ and $C$, was utilized in the analytical models. Malaria RDT results were included in the analytical models given their direct relation to the treatment exposure of interest. Country of treatment and oral rehydration solution (ORS) were also included in the models..

Sensitivity analyses, using both stratified and alternative predictor approaches, were completed using adjusted regression modeling as in the primary analysis. This approach has been used in other similar research $[37,38]$. One sensitivity analysis assessed the effect of artemether-lumefantrine within the first $48 \mathrm{~h}$ of ETU admission stratified based on malaria RDT categorization of negative or unknown. Another analysis stratified the models based on the three possible $\mathrm{CT}$ value results, and a final sensitivity analysis evaluated the use of intravenous (IV) antimalarial medications alone or in addition to oral treatment as compared to oral antimalarial medications alone. Due to an identified significant correlation between oral antimalarial administration and paracetamol an additional model incorporating paracetamol as an alternative predictor was performed.

\section{Results}

From patients treated at the five ETUs, 478 had EVD, and of these 424 were eligible for inclusion (Fig. 1). The average age was 30.5 years ( $\mathrm{SD} \pm 18.7$ years), and the population was $59.7 \%$ female. Overall, the most commonly observed clinical signs and symptoms were diarrhea 298 (70.3\%), dysphagia 171 (40.3\%), and dyspnea 135 (31.8\%). High CT value (low viral loads) were found in 122 (43.4\%) of the 281 patients with CT value results, while 159 (56.6\%) had low CT values (high viral load). Malaria RDT assessments were carried out on 243 (57.3\%) patients, with $48(19.8 \%)$ having a positive result (Table 1$)$.

\section{Antimalarial treatments}

A total of 391 (92.2\%) of the overall 424 patients studied received antimalarial treatment at any time point during care. Of those, $11(2.6 \%)$ patients received only IV antimalarials while $31(7.9 \%)$ were treated with both oral and IV antimalarial medications. Early oral antimalarials initiated within the first $48 \mathrm{~h}$ of care were provided to 376 cases $(88.7 \%)$. Evidence of differences were observed between those treated and those not treated with early oral antimalarials based on the country of treatment, receipt of ORS $(\mathrm{p}<0.001)$, cefixime $(\mathrm{p}<0.001)$, multivitamins $(\mathrm{p}<0.001)$, vitamin $\mathrm{C}(\mathrm{p}<0.001)$, and vitamin $A$ $(\mathrm{p}<0.001)$; and those with abnormal bleeding $(\mathrm{p}=0.001)$ as compared to those without (Table 2). There was no evidence of oral antimalarial treatment difference among those with different Malaria RDT values or CT values, compared between all groups in each category.

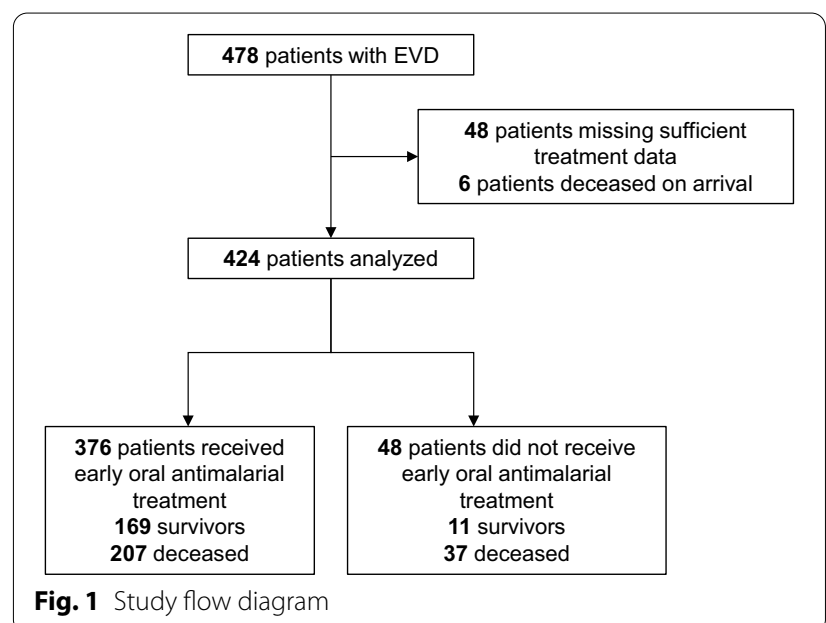


Table 1 Cohort characteristics

\begin{tabular}{|c|c|}
\hline & n (\%) \\
\hline Age $\left(\right.$ years) ${ }^{*}$ & $30.5( \pm 18.7)$ \\
\hline \multicolumn{2}{|l|}{ Sex } \\
\hline Female & $253(59.7)$ \\
\hline Male & $171(40.3)$ \\
\hline Length of stay (days) $^{\dagger}$ & $7(4,12)$ \\
\hline \multicolumn{2}{|l|}{ Country of treatment } \\
\hline Sierra Leone & $290(68.4)$ \\
\hline Liberia & $134(31.6)$ \\
\hline \multicolumn{2}{|c|}{ Rapid diagnostic test for malaria results } \\
\hline Positive & $48(11.3)$ \\
\hline Negative & $195(46.0)$ \\
\hline Not Tested & $181(42.7)$ \\
\hline \multicolumn{2}{|c|}{ Cycle threshold value /viral load } \\
\hline$\geq 22$ (Low Viral Load) & $122(28.8)$ \\
\hline$<22$ (High Viral Load) & $159(37.5)$ \\
\hline Missing & $143(33.7)$ \\
\hline \multicolumn{2}{|c|}{ Treatments received in the first 48 hours of care } \\
\hline Artemether-lumefantrine & $376(88.7)$ \\
\hline ORS & $373(88.0)$ \\
\hline Cefixime & $360(84.9)$ \\
\hline Multivitamins & $261(61.6)$ \\
\hline Ondansetron & $111(26.2)$ \\
\hline Vitamin C & $383(90.3)$ \\
\hline Zinc Sulphate & $22(5.2)$ \\
\hline Paracetamol & $399(94.1)$ \\
\hline Vitamin A & $330(77.8)$ \\
\hline \multicolumn{2}{|c|}{ Signs \& symptoms in the first 48 hours of care } \\
\hline Abnormal Bleeding & $122(28.8)$ \\
\hline Coma & $6(1.4)$ \\
\hline Diarrhea & $298(70.3)$ \\
\hline Dysphagia & $171(40.3)$ \\
\hline Dyspnea & $135(31.8)$ \\
\hline Jaundice & $25(5.9)$ \\
\hline Anorexia & $283(66.7)$ \\
\hline Abdominal Pain & $265(62.5)$ \\
\hline Vomiting & $254(59.9)$ \\
\hline
\end{tabular}

*Values represent mean with standard deviation

${ }^{\dagger}$ Values represent median with interquartile range

\section{Mortality outcomes}

Of the 424 patients included in this analysis, 244 (57.5\%) died during treatment, including 207 (55.1\%) of the 376 that received oral antimalarials in the first $48 \mathrm{~h}$ of care and $37(77.1 \%)$ of the 48 that did not receive oral antimalarials in the first $48 \mathrm{~h}$ of care. Across the five ETU sites in Sierra Leone and Liberia, 290 patients were treated in Sierra Leone and 134 were treated in Liberia. Of the patients in Sierra Leone, 171 (59.0\%) died during treatment, and of those in Liberia, 73 (54.5\%) died during treatment (Fig. 2). There was no evidence of mortality difference between the two countries ( $p=0.399$, Table 3$)$.

Having a high CT value (low viral load) was associated with decreased mortality as compared with having a low CT value or missing CT value. Overall, there were no evidence of differences in Malaria RDT status among those who died as compared to those that lived. Treatment with ORS, cefixime, multivitamins and Vitamin A all had evidence of association with decreased mortality, and increased mortality was associated with patients having signs and symptoms of abnormal bleeding, coma, diarrhea dysphagia, dyspnea, and jaundice (Table 3). In multivariable regression modeling, adjusting for the covariates of age, CT value, bleeding, diarrhea, dyspnea, dysphagia, country of treatment, Malaria RDT status, treatments with cefixime, ORS, and MVI, oral antimalarial treatment provided within the first $48 \mathrm{~h}$ of care was associated with reduced mortality $(\mathrm{aOR}=0.34,95 \% \mathrm{CI}$ : $0.12,0.92 ; \mathrm{p}=0.039$ ).

\section{Sensitivity analysis}

Among patients with a negative malaria RDT result, there was no evidence of an association identified with mortality for patients receiving early oral antimalarial treatment ( $\mathrm{aOR}=0.57,95 \% \mathrm{CI}: 0.16,2.0, \mathrm{p}=0.385$; Additional file 2). In the analysis of cases in which RDT were not performed, evidence of an association with reduced mortality was observed (aOR $=0.05,95 \% \mathrm{CI}$ : 0.00, 0.60, $\mathrm{p}=0.034$ ). In stratified sensitivity analyses based on CT value results, there was no observed reduction in mortality across the three categories (low viral loads, high viral load or missing). In assessing the impact of IV treatment, as compared to oral antimalarial treatment alone, no association was identified with mortality $(\mathrm{aOR}=0.55$, 95\% CI: 0.19, 1.53, $\mathrm{p}=0.256$ ). Running the multivariate model with the addition of paracetamol as a predictor there was no observed association with mortality outcomes $(\mathrm{aOR}=0.79,95 \% \mathrm{CI}: 0.21,2.84, \mathrm{p}=0.726)$.

\section{Discussion}

Although there now exist effective, targeted therapeutics for use in EVD [41], supportive care and utilization of non-EVD specific antimicrobials is recommended in clinical management. However, many of these recommendations, including empirical treatment for malaria infection in EVD outbreaks, are based on limited patient-centered evidence. The data from the current multisite analysis demonstrates that when controlling for confounding factors, there is evidence that treatment with early oral antimalarials was associated with a decrease in mortality. These findings support current treatment guidelines which call for empiric antimalarial medications provided to patients being cared for in EVD outbreak settings. 
Table 2 Cohort characteristics stratified by early oral antimalarial treatment exposure

\begin{tabular}{|c|c|c|c|}
\hline & Treated $(n=376, \%)$ & Untreated $(n=48, \%)$ & P-value \\
\hline Age (years) ${ }^{*}$ & $31.2 \pm 18.8$ & $23.0 \pm 15.9$ & 0.001 \\
\hline \multicolumn{4}{|l|}{ Sex } \\
\hline Female & $223(59.3)$ & $30(62.5)$ & \multirow[t]{2}{*}{0.756} \\
\hline Male & $153(40.7)$ & $18(37.5)$ & \\
\hline Length of Stay (days) $^{\dagger}$ & $7,(4,12)$ & $5,(1,8)$ & 0.216 \\
\hline \multicolumn{4}{|l|}{ Country of Treatment } \\
\hline Sierra Leone & $249(66.2)$ & $41(85.4)$ & \multirow[t]{2}{*}{0.008} \\
\hline Liberia & $127(33.8)$ & $7(14.6)$ & \\
\hline \multicolumn{4}{|c|}{ Rapid diagnostic test for malaria results } \\
\hline Positive & $45(12.0)$ & $3(6.3)$ & \multirow[t]{3}{*}{0.177} \\
\hline Negative & $167(44.4)$ & $28(58.3)$ & \\
\hline Not Tested & $164(43.6)$ & $17(35.4)$ & \\
\hline \multicolumn{4}{|c|}{ Cycle threshold value /viral load } \\
\hline$\geq 22$ (Low Viral Load) & $112(29.8)$ & $10(20.8)$ & \multirow[t]{3}{*}{0.162} \\
\hline$<22$ (High Viral Load) & $135(35.9)$ & $24(50.0)$ & \\
\hline Missing & $129(34.3)$ & $14(29.2)$ & \\
\hline \multicolumn{4}{|c|}{ Treatments received first 48 hours of care } \\
\hline ORS & $350(93.1)$ & $23(47.9)$ & 0.000 \\
\hline Cefixime & $342(91.0)$ & $18(37.5)$ & 0.000 \\
\hline Multivitamins & $243(64.6)$ & $18(37.5)$ & 0.000 \\
\hline Ondansetron & $97(25.8)$ & $14(29.2)$ & 0.604 \\
\hline Vitamin C & $357(94.9)$ & $26(54.2)$ & 0.000 \\
\hline Zinc Sulphate & $19(5.1)$ & $3(6.3)$ & 0.727 \\
\hline Vitamin A & $315(83.8)$ & $15(31.3)$ & 0.000 \\
\hline \multicolumn{4}{|c|}{ Signs \& symptoms first 48 hours of care } \\
\hline Abnormal Bleeding & $98(26.1)$ & $24(50.0)$ & 0.001 \\
\hline Coma & $2(0.5)$ & $4(8.3)$ & 0.002 \\
\hline Diarrhea & $266(70.7)$ & $32(66.7)$ & 0.615 \\
\hline Dysphagia & $152(40.4)$ & $19(39.6)$ & 1.00 \\
\hline Dyspnea & $117(31.1)$ & $18(37.5)$ & 0.753 \\
\hline Jaundice & $22(5.9)$ & $3(6.3)$ & 0.754 \\
\hline Anorexia & $252(67.0)$ & $31(64.6)$ & 0.747 \\
\hline Abdominal Pain & $237(63.0)$ & $28(58.3)$ & 0.530 \\
\hline Vomiting & $223(59.3)$ & 31 (64.6) & 0.534 \\
\hline
\end{tabular}

*Values represent mean with standard deviation

${ }^{\dagger}$ Values represent median with interquartile range

There is only minimal and conflicting existing data on the impact of antimalarial agents on patient-centered outcomes in EVD [13]. A serologic analysis from a single ETU in Liberia found that plasmodium species parasitemia was associated with increased survival in EVD cases independent of treatment with antimalarial exposure [46]. Gignoux et al. found that among EVD-positive patients, the adjusted risk of death was reduced in patients treated with artesunate-amodiaquine versus artemether-lumefantrine [13]. This effect was strongest in EVD-positive patients without malaria co-infection [13]. The authors suggest that this effect may be explained either by activity of amodiaquine against the EBOV, as has been shown in vitro, or another confounding effect [13, 27, 29]. Garbern et al. found that, in analyzing data from a population that received community-level mass drug administrations of antimalarial treatments in West Africa, there was a no evidence of change in mortality among patients treated with artesunate-amodiaquine [35]. However, the findings from the current data support the hypothesis that antimalarials confer a beneficial effect in patients with EVD. Furthermore, in the sensitivity analysis, evidence of a protective association was found among patients lacking RDT results and a lack of 


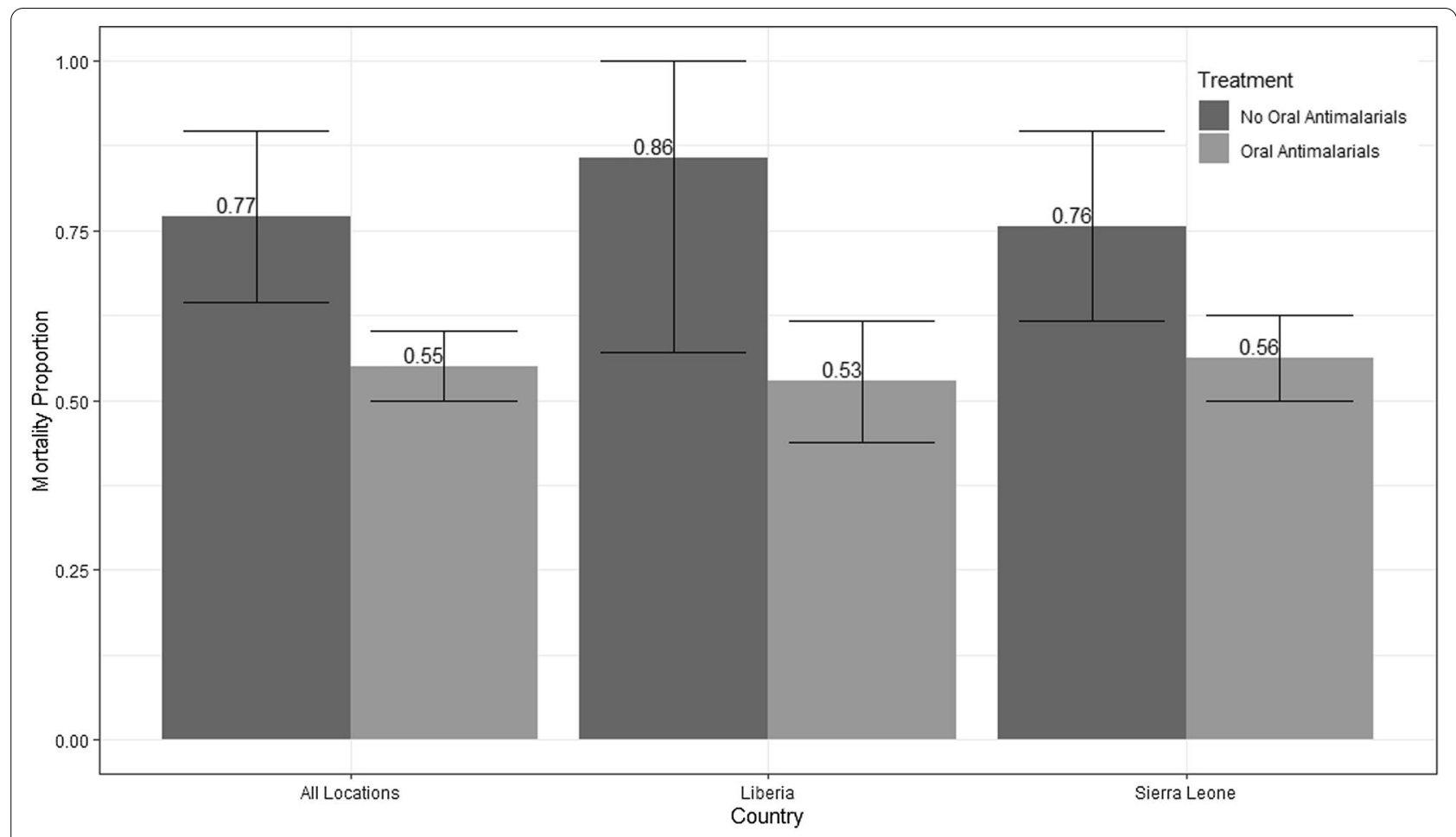

Fig. 2 Proportional mortality outcomes by country with 95\% confidence intervals

protective association was noted using the same predictive model with paracetamol, a medication which had statistically significant association with oral antimalarial administration. Insignificant protective effects were noted across sensitivity analyses stratified by all CT value results as well as early in those receiving oral antimalarial treatment with artemether-lumefantrine in the subgroup of patients with a negative malaria RDT result in which the point estimates were in favor of mortality benefit with early oral antimalarial treatment. The lack of evidence in the sensitivity analysis may be due to a type II error derived from the smaller sample sizes in the stratified analyses or could be due to statistical chance. Although there was evidence of an association between a reduction in mortality and early oral anti-malarial treatment, the sensitivity analysis did not yield evidence of this association in RDT negative patients and the literature base is conflicting. The current results should be reinforced by additional prospective studies, drawn from EBV outbreak settings applying standardized international guidelines, for external validation evaluating treatment with artemether-lumefantrine among cases with and without malarial disease in EVD outbreak response care.

A study using computer modeling by Ekins et al. found that the antimalarials chloroquine and amodiaquine had favorable antimalarial binding to a protein site likely in EBOV and other filoviruses [47]. Similarly, Goyal et al. demonstrated in vitro inhibition of EBOV by chloroquine and amodiaquine [48]. Although research on artemether-lumefantrine does not specifically exist, the laboratory data indicate that there is a potential biologic activity for EBOV treatment with antimalarial drugs. Given the limited data on the patient-centered impacts of other antimalarial medications, further studies of not only artemether-lumefantrine but other commonly available malaria treatment regimens would be beneficial to inform this area of research.

IV administration of antimalarial medications are the preferred route when patients are experiencing severe illness due to malaria [49]. In severe malaria, gastrointestinal intolerance and erratic intestinal absorption can occur, which may make the use of oral medications unreliable or ineffective [50]. This can be further compounded by coinfection with EVD, where large-volume gastrointestinal fluid loss can occur [49]. Although the regression analysis evaluation of the addition of IV antimalarial treatment found no evidence of impact on mortality, the number of subjects receiving IV treatment were small and those receiving IV medications were likely to have more severe illness, which may not have been adequately controlled for in the modeling approach. As such, definitive understanding of the role of IV antimalarial treatments cannot be concluded from the available data and this treatment approach warrants further study. 
Table 3 Cohort characteristics stratified by mortality outcomes

\begin{tabular}{|c|c|c|c|}
\hline & Survived $(n=180, \%)$ & $\operatorname{Died}(n=244, \%)$ & p-value \\
\hline Age (years)* & $28.7 \pm 15.3$ & $31.8 \pm 20.8$ & 0.080 \\
\hline \multicolumn{4}{|l|}{ Sex } \\
\hline Female & $108(60.0)$ & $145(59.4)$ & \multirow[t]{2}{*}{0.921} \\
\hline Male & $72(40.0)$ & $99(40.6)$ & \\
\hline Length of Stay (days) ${ }^{\dagger}$ & $13,(10,17)$ & $4,(3,6)$ & 0.000 \\
\hline \multicolumn{4}{|l|}{ Country of Treatment } \\
\hline Sierra Leone & $119(66.1)$ & $171(70.1)$ & \multirow[t]{2}{*}{0.399} \\
\hline Liberia & $61(33.9)$ & $73(29.9)$ & \\
\hline \multicolumn{4}{|c|}{ Rapid diagnostic test for malaria results } \\
\hline Positive & $17(9.4)$ & $31(12.7)$ & \multirow[t]{3}{*}{0.082} \\
\hline Negative & $94(52.2)$ & $101(41.4)$ & \\
\hline Not Tested & $69(38.3)$ & $112(45.9)$ & \\
\hline \multicolumn{4}{|c|}{ Cycle Threshold Value Niral Load } \\
\hline$\geq 22$ (Low Viral Load) & $81(45.0)$ & $41(16.8)$ & \multirow[t]{3}{*}{0.000} \\
\hline$<22$ (High Viral Load) & $50(27.8)$ & $109(44.7)$ & \\
\hline Missing & $49(27.2)$ & $94(38.5)$ & \\
\hline \multicolumn{4}{|c|}{ Treatments received first 48 hours of care } \\
\hline Artemether-lumefantrine & $169(93.9)$ & $207(84.8)$ & 0.005 \\
\hline ORS & $166(92.2)$ & $207(84.8)$ & 0.023 \\
\hline Cefixime & $163(90.6)$ & $197(80.7)$ & 0.006 \\
\hline Multivitamins & $121(67.2)$ & $140(57.4)$ & 0.044 \\
\hline Ondansetron & $48(26.7)$ & $63(25.8)$ & 0.911 \\
\hline Vitamin C & $164(92.8)$ & $219(89.8)$ & 0.740 \\
\hline Zinc Sulphate & $7(3.9)$ & $15(6.1)$ & 0.378 \\
\hline Vitamin A & $152(84.4)$ & $178(73.0)$ & 0.006 \\
\hline \multicolumn{4}{|c|}{ Signs \& symptoms first 48 hours of care } \\
\hline Abnormal Bleeding & $42(23.3)$ & $80(32.8)$ & 0.039 \\
\hline Coma & $0(0.0)$ & $6(2.5)$ & 0.041 \\
\hline Diarrhea & $111(61.7)$ & $187(76.6)$ & 0.001 \\
\hline Dysphagia & $60(33.3)$ & $111(45.5)$ & 0.012 \\
\hline Dyspnea & $41(22.8)$ & $94(38.5)$ & 0.001 \\
\hline Jaundice & $2(1.1)$ & $23(9.4)$ & 0.000 \\
\hline Anorexia & $116(64.4)$ & $167(68.4)$ & 0.405 \\
\hline Abdominal Pain & $108(60.0)$ & $157(64.3)$ & 0.363 \\
\hline Vomiting & $104(57.8)$ & $150(61.5)$ & 0.483 \\
\hline
\end{tabular}

*Values represent mean with standard deviation

${ }^{\dagger}$ Values represent median with interquartile range

\section{Limitations and strengths}

The study has limitations that must be taken into consideration. Treatment with oral antimalarials was not administered in a random approach but rather when the resources were available, potentially allowing for selection bias. This was controlled for as best as possible within the scope of this data with regression analyses, but residual impacts from unidentified confounders are still possible. Additionally, the data did not allow for evaluation of dose-response effects and treatment durations which could be important factors in patient outcomes that warrant further study. All of the patients in this study were treated in the context of IMC operated ETUs, leading to both a standardization of care and data collection, but potentially a decrease in the generalizability of the findings. Country of treatment was controlled for, but, given the limitations of the data, it was not possible to have more granular location control. However, the protocols used at the clinical sites were based on international guidelines and as such the data are likely generalizable to outbreak populations in similar environments where care is generally informed by international recommendations. 
One of the strengths of this study is that it is able to draw on validated patient data from a robust database where patient care was standardized across all ETUs. In this, we would like to acknowledge the diligent work done by those who collected this data across all of the ETUs. This study is also able to provide insight into an area where it is not feasible to conduct a randomized control trial to assess outcomes.

\section{Conclusion}

This current study found that artemether-lumefantrine administered early in ETU care in an outbreak setting was associated with decreased mortality in patients with EVD. These data support the empiric provision of antimalarial medications, as currently recommended by international guidelines, however additional prospective studies, in epidemic settings following international guidelines, would be beneficial to validate these findings and enhance our understanding of the impacts of other routes of administration and alternative antimalarial treatment regimes.

\author{
Abbreviations \\ EVD: Ebola virus disease; ETUs: Ebola Treatment Units; WHO: World Health \\ Organization; EBOV: Ebola Virus; IMC: International Medical Corps; RDT: Rapid \\ diagnostic test; RT-PCR: Reverse transcription polymerase chain reaction; \\ CT: Cycle threshold; IQR: Interquartile ranges; aORs: Adjusted odds ratios; Cl: \\ Confidence intervals; MVI: Multivitamin; ORS: Oral rehydration solution; IV: \\ Intravenous.
}

\section{Supplementary Information}

The online version contains supplementary material available at https://doi. org/10.1186/s12879-021-06811-3.

Additional file 1. International medical corps clinical management guidelines.

Additional file 2. Sensitivity analyses for mortality outcomes.

\section{Acknowledgements}

We would like to thank International Medical Corps and the Governments of Liberia and Sierra Leone for contributing data for this research. We also thank all the generous institutional, corporate, foundation, and individual donors who placed their confidence and trust in International Medical Corps and made its work during the Ebola epidemic possible. We thank the United States Naval Medical Research Center, Public Health England, the European Union Mobile Laboratory, and the Nigerian Laboratory for providing laboratory support to International Medical Corps Ebola Treatment Units in Liberia and Sierra Leone and making their data available for this research. Finally, we thank all the International Medical Corps staff in Liberia and Sierra Leone, including the data collection officers at each Ebola treatment unit, without whom this data would not be available for analysis.

\section{Authors' contributions}

$L A, A C L$, ARA designed the research study. SMP, SBK, MM, FS, and $A C L$ supervised the data collection. $L A, S M P, D Y, S B K, M M, F S, D W, T L, A C L$ and ARA managed and analyzed the data. LA, SMP, DY, SG, SBK, MM, FS, DW, TL, $A C L$, and ARA drafted the manuscript. All authors read and approved the final manuscript.

\section{Funding}

Funding for this study was provided by the National Institutes of Health $(\mathrm{NIH})$ National Institute of Allergy and Infectious Diseases (R03Al132801 and R25Al140490).

\section{Availability of data and materials}

Data can be made available upon request from the corresponding author.

\section{Declarations}

\section{Ethics approval and consent to participate}

Ethical approval was obtained from the Sierra Leone Ethics and Scientific Review Committee, the University of Liberia and Rhode Island Hospital Institutional Review Boards. The methods of this study were performed in accordance with relevant guidelines and regulations for research and conformed to the Declaration of Helsinki. As the study was retrospective and deemed minimal risk by the ethical review boards informed consent was not obtained.

\section{Consent for publication}

Not applicable.

\section{Competing interests}

The authors have no competing interests to declare. The content of this manuscript is solely the responsibility of the authors and does not necessarily represent the views of International Medical Corps or any governmental bodies or academic organizations.

\section{Author details}

${ }^{1}$ Warren Alpert Medical School of Brown University, Providence, RI, USA. ${ }^{2}$ International Medical Corps, Washington, DC, USA. ${ }^{3}$ Center for Statistical Sciences, Department of Biostatistics, Brown University School of Public Health, Providence, RI, USA. ${ }^{4}$ Department of Emergency Medicine, Warren Alpert Medical School of Brown University, 55 Claverick Street, Room 274, Providence, RI 02903, USA. ${ }^{5}$ Ministry of Health, Monrovia, Liberia. ${ }^{6}$ College of Medicine and Allied Health Sciences, University of Sierra Leone, Freetown, Sierra Leone.

Received: 18 January 2021 Accepted: 21 October 2021

Published online: 20 January 2022

\section{References}

1. Ebola virus disease [Internet]. https://www.who.int/en/news-room/ fact-sheets/detail/ebola-virus-disease. Accessed 16 Mar 2019.

2. Barry M, Traoré FA, Sako FB, Kpamy DO, Bah El, Poncin M, et al. Ebola outbreak in Conakry, Guinea: epidemiological, clinical, and outcome features. Med Mal Infect. 2014;44(11-12):491-4

3. Hunt L, Gupta-Wright A, Simms V, Tamba F, Knott V, Tamba K, et al. Clinical presentation, biochemical, and haematological parameters and their association with outcome in patients with Ebola virus disease: an observational cohort study. Lancet Infect Dis. 2015;15(11):1292-9.

4. Arranz J, Lundeby KM, Hassan S, Fuentes LMZ, Garcés PSJ, Haaskjold $Y L$, et al. Clinical features of suspected Ebola cases referred to the Moyamba ETC, Sierra Leone: Challenges in the later stages of the 2014 outbreak. BMC Infect Dis. 2016;16(1):308.

5. de Wit E, Kramer S, Prescott J, Rosenke K, Falzarano D, Marzi A, et al. Clinical chemistry of patients with Ebola in monrovia. Liberia J Infect Dis. 2016;214(suppl 3):S303-7.

6. Li W-G, Chen W-W, Li L, Ji D, Ji Y-J, Li C, et al. The etiology of Ebola virus disease-like illnesses in Ebola virusnegative patients from Sierra Leone. Oncotarget. 2016;7(19):27910-5.

7. Waxman M, Aluisio AR, Rege S, Levine AC. Characteristics and survival of patients with Ebola virus infection, malaria, or both in Sierra Leone: a retrospective cohort study. Lancet Infect Dis. 2017;17(6):654-60.

8. $\mathrm{WHO} \mid$ Optimized Supportive Care for Ebola Virus Disease [Internet]. WHO. http://www.who.int/csr/resources/publications/optimizedsupportive-care/en/. Accessed 9 Mar 2020.

9. Ansumana $\mathrm{R}$, Jacobsen $\mathrm{KH}$, Sahr F, Idris M, Bangura $\mathrm{H}$, Boie-Jalloh $\mathrm{M}$, et al. Ebola in Freetown area, Sierra Leone-a case study of 581 patients. N Engl J Med. 2015;372(6):587-8. 
10. Bah El, Lamah M-C, Fletcher T, Jacob ST, Brett-Major DM, Sall AA, et al. Clinical presentation of patients with Ebola virus disease in Conakry. Guinea N Engl J Med. 2015;372(1):40-7.

11. Dallatomasina S, Crestani R, Sylvester Squire J, Declerk H, Caleo GM, Wolz A, et al. Ebola outbreak in rural West Africa: epidemiology, clinical features and outcomes. Trop Med Int Health TM IH. 2015;20(4):448-54.

12. Damkjær M, Rudolf F, Mishra S, Young A, Storgaard M. Clinical features and outcome of Ebola virus disease in pediatric patients: a retrospective case series. J Pediatr. 2017;182:378-381.e1.

13. Gignoux E, Azman AS, de Smet M, Azuma P, Massaquoi M, Job D, et al. Effect of artesunate-amodiaquine on mortality related to Ebola virus disease. N Engl J Med. 2016;374(1):23-32.

14. Guimard Y, Bwaka MA, Colebunders R, Calain P, Massamba M, De Roo A, et al. Organization of patient care during the Ebola hemorrhagic fever epidemic in Kikwit, Democratic Republic of the Congo, 1995. J Infect Dis. 1999;179(Suppl 1):S268-273.

15. Leligdowicz A, Fischer WA, Uyeki TM, Fletcher TE, Adhikari NKJ, Portella $\mathrm{G}$, et al. Ebola virus disease and critical illness. Crit Care Lond Engl. 2016;20(1):217.

16. Levine AC, Shetty PP, Burbach R, Cheemalapati S, Glavis-Bloom J, Wiskel $T$, et al. Derivation and internal validation of the Ebola prediction score for risk stratification of patients with suspected ebola virus disease. Ann Emerg Med. 2015;66(3):285-293.e1.

17. Liddell AM, Davey RT, Mehta AK, Varkey JB, Kraft CS, Tseggay GK, et al. Characteristics and clinical management of a cluster of 3 patients with Ebola virus disease, including the first domestically acquired cases in the United States. Ann Intern Med. 2015;163(2):81-90.

18. Lyon GM, Mehta AK, Varkey JB, Brantly K, Plyler L, McElroy AK, et al. Clinical care of two patients with Ebola virus disease in the United States. N Engl J Med. 2014;371(25):2402-9.

19. Mupapa K, Massamba M, Kibadi K, Kuvula K, Bwaka A, Kipasa M, et al. Treatment of Ebola hemorrhagic fever with blood transfusions from convalescent patients. J Infect Dis. 1999;179:S18-23.

20. Schieffelin JS, Shaffer JG, Goba A, Gbakie M, Gire SK, Colubri A, et al. Clinical illness and outcomes in patients with Ebola in Sierra Leone. N Engl J Med. 2014;371(22):2092-100.

21. Shao X, Ren W, Zhou F. Clinical presentation and care of patients with Ebola virus disease in the china Ebola treatment unit. Liberia Jpn J Infect Dis. 2017;70(1):32-7.

22. Uyeki TM, Mehta AK, Davey RT, Liddell AM, WolfT, Vetter P, et al. Clinical Management of Ebola virus disease in the United States and Europe. N Engl J Med. 2016:374(7):636-46.

23. Ebola Situation Reports | Ebola [Internet]. http://apps.who.int/ebola/ ebola-situation-reports. Accessed 28 Sep 2019.

24. Akpovwa H. Chloroquine could be used for the treatment of filoviral infections and other viral infections that emerge or emerged from viruses requiring an acidic $\mathrm{pH}$ for infectivity. Cell Biochem Funct. 2016;34(4):191-6.

25. Al-Bari MAA. Targeting endosomal acidification by chloroquine analogs as a promising strategy for the treatment of emerging viral diseases. Pharmacol Res Perspect. 2017;5(1):e00293.

26. Bishop BM. Potential and emerging treatment options for Ebola virus disease. Ann Pharmacother. 2015:49(2):196-206.

27. Kouznetsova J, Sun W, Martínez-Romero C, Tawa G, Shinn P, Chen CZ, et al. Identification of 53 compounds that block Ebola virus-like particle entry via a repurposing screen of approved drugs. Emerg Microbes Infect. 2014;3(12):e84.

28. Long J, Wright E, Molesti E, Temperton N, Barclay W. Antiviral therapies against Ebola and other emerging viral diseases using existing medicines that block virus entry. F1000Res. 2015;4:30.

29. Zilbermintz L, Leonardi W, Jeong S-Y, Sjodt M, McComb R, Ho C-LC, et al. Identification of agents effective against multiple toxins and viruses by host-oriented cell targeting. Sci Rep. 2015;5:13476.

30. Sakurai Y, Sakakibara N, Toyama M, Baba M, Davey RA. Novel amodiaquine derivatives potently inhibit Ebola virus infection. Antiviral Res. 2018;160:175-82.

31. Dowall SD, Bosworth A, Watson R, Bewley K, Taylor I, Rayner E, et al. Chloroquine inhibited Ebola virus replication in vitro but failed to protect against infection and disease in the in vivo guinea pig model. J Gen Virol. 2015;96(12):3484-92.
32. Falzarano D, Safronetz D, Prescott J, Marzi A, Feldmann F, Feldmann H. Lack of protection against ebola virus from chloroquine in mice and hamsters. Emerg Infect Dis. 2015;21(6):1065-7.

33. Madrid PB, Chopra S, Manger ID, Gilfillan L, Keepers TR, Shurtleff AC, et al. A systematic screen of FDA-approved drugs for inhibitors of biological threat agents. PLoS ONE. 2013;8(4):e60579.

34. Madrid PB, Panchal RG, Warren TK, Shurtleff AC, Endsley AN, Green CE, et al. Evaluation of Ebola virus inhibitors for drug repurposing. ACS Infect Dis. 2015;1(7):317-26.

35. Garbern SC, Yam D, Aluisio AR, Cho DK, Kennedy SB, Massaquoi M, et al. Effect of mass artesunate-amodiaquine distribution on mortality of patients with Ebola virus disease during west african outbreak. Open Forum Infect Dis. 2019. https://doi.org/10.1093/ofid/ofz250.

36. Roshania R, Mallow M, Dunbar N, Mansary D, Shetty P, Lyon T, et al. Successful implementation of a multicountry clinical surveillance and data collection system for Ebola virus disease in West Africa: findings and lessons learned. Glob Health Sci Pract. 2016;4(3):394-409.

37. Aluisio AR, Yam D, Peters JL, Cho DK, Perera SM, Kennedy SB, et al. Impact of intravenous fluid therapy on survival among patients with ebola virus disease: an international multisite retrospective cohort study. Clin Infect Dis Off Publ Infect Dis Soc Am. 2020;70(6):1038-47.

38. Vitamin A Supplementation Was Associated with Reduced Mortality in Patients with Ebola Virus Disease during the West African Outbreak | The Journal of Nutrition | Oxford Academic [Internet]. https://academic.oup. com/jn/article/149/10/1757/5527780. Accessed 20 Jun 2020.

39. International Medical Corps. Standard clinical/psychosocial procedures for Ebola treatment unit (ETU) operations. Los Angeles: International Medical Corps; 2016.

40. BinaxNOW Malaria - Alere is now Abbott [Internet]. https://www.alere com/en/home/product-details/binaxnow-malaria.html. Accessed $28 \mathrm{Mar}$ 2020.

41. Mulangu S, Dodd LE, Davey RT, Tshiani Mbaya O, Proschan M, Mukadi D, et al. A randomized, controlled trial of Ebola virus disease therapeutics. N Engl J Med. 2019;381(24):2293-303.

42. RStudio [Internet]. https://rstudio.com/. Accessed 28 Oct 2019.

43. Skrable K, Roshania R, Mallow M, Wolfman V, Siakor M, Levine AC. The natural history of acute Ebola Virus Disease among patients managed in five Ebola treatment units in West Africa: A retrospective cohort study. PLoS Negl Trop Dis. 2017;1 1(7):e0005700.

44. Yam D, Aluisio AR, Perera SM, Peters JL, Cho DK, Kennedy SB, et al. Association between multivitamin supplementation and mortality among patients with Ebola virus disease: an international multisite cohort study. Afr J Emerg Med. 2020;10(1):23-9.

45. Aluisio AR, Perera SM, Yam D, Garbern S, Peters $J$, Abel L, et al. Association between treatment with oral third-generation cephalosporin antibiotics and mortality outcomes in Ebola virus disease: a multinational retrospective cohort study. Trop Med Int Health TM IH. 2020;25(4):433-41.

46. Rosenke K, Adjemian J, Munster VJ, Marzi A, Falzarano D, Onyango CO, et al. Plasmodium parasitemia associated with increased survival in Ebola virus-infected patients. Clin Infect Dis Off Publ Infect Dis Soc Am. 2016;63(8):1026-33.

47. Ekins S, Freundlich JS, Coffee M. A common feature pharmacophore for FDA-approved drugs inhibiting the Ebola virus. F1000Res. 2014;3:277.

48. Goyal S, Binnington B, McCarthy SDS, Desmaële D, Férrié L, Figadère $B$, et al. Inhibition of in vitro Ebola infection by anti-parasitic quinoline derivatives. F1000Res. 2020;9:268.

49. Clinical management of patients with viral haemorrhagic fever: A pocket guide for front-line health workers | ENN [Internet]. https://www.ennon line.net/vhfpocketguide. Accessed 28 Sep 2019.

50. Trampuz A, Jereb M, Muzlovic I, Prabhu RM. Clinical review: severe malaria. Crit Care. 2003;7(4):315.

\section{Publisher's Note}

Springer Nature remains neutral with regard to jurisdictional claims in published maps and institutional affiliations. 